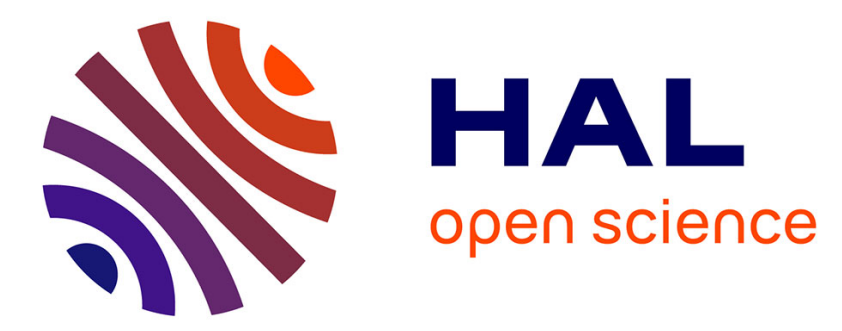

\title{
Investigation of the mechanical behaviour of Ti-6Al-4V alloy under hot forming conditions: Experiment and modelling
}

\author{
Vincent Velay, H. Matsumoto, L. Sasaki, Vanessa Vidal
}

\section{To cite this version:}

Vincent Velay, H. Matsumoto, L. Sasaki, Vanessa Vidal. Investigation of the mechanical behaviour of Ti-6Al-4V alloy under hot forming conditions: Experiment and modelling. Materials Science and Engineering Technology / Materialwissenschaft und Werkstofftechnik, 2014, 45 (9), p. 847-853. 10.1002/mawe.201400293 . hal-01611987

\section{HAL Id: hal-01611987 \\ https://hal.science/hal-01611987}

Submitted on 7 Nov 2018

HAL is a multi-disciplinary open access archive for the deposit and dissemination of scientific research documents, whether they are published or not. The documents may come from teaching and research institutions in France or abroad, or from public or private research centers.
L'archive ouverte pluridisciplinaire HAL, est destinée au dépôt et à la diffusion de documents scientifiques de niveau recherche, publiés ou non, émanant des établissements d'enseignement et de recherche français ou étrangers, des laboratoires publics ou privés. 


\title{
Investigation of the mechanical behaviour of Ti-6Al-4V alloy under hot forming conditions: Experiment and modelling
}

\section{Untersuchung des mechanischen Verhaltens von Ti6Al4V-Legierungen unter Warmumformungsbedingungen: Versuch und Modellierung}

\begin{abstract}
V. Velay ${ }^{1}$, H. Matsumoto ${ }^{2,3}{ }^{3}$, L. Sasaki ${ }^{1}$, V. Vidal ${ }^{1}$
The present investigation aims at evaluating and understanding the formability of Ti-6Al-4V alloy under hot forming conditions $\left(650^{\circ} \mathrm{C} \leq \mathrm{T} \leq 750^{\circ} \mathrm{C}\right)$. To fulfil these objectives, it was necessary to establish accurate material models and predict microscopic material evolution depending on temperature and strain rate. Two kinds of microstructure were investigated, the first one considers a conventional grain size of the $\alpha$-phase $(3 \mu \mathrm{m})$ whereas a combined forging-rolling process is used to elaborate the second one and allows to obtain a very fine grain of the $\alpha$-phase $(0.5 \mu \mathrm{m})$. In this research work, we propose to investigate the capabilities of the titanium alloy under forming conditions quite different from those usually considered in superplastic forming process (lower temperatures and higher strain rates).
\end{abstract}

Keywords: Mechanical behaviour / hot forming / behaviour modelling / titanium alloys

Schlüsselwörter: Mechanisches Verhalten / Warmumformung /

Modellierungsverhalten / Titanlegierungen

\section{Introduction}

Most of time, titanium alloys are more difficult to form. However, if sheet metal forming is performed under favourable conditions, they can be successfully formed into complex parts. Such conditions correspond to a high forming temperature (greater than $900{ }^{\circ} \mathrm{C}$ ) and low strain rates (less than $10^{-3} \mathrm{~s}^{-1}$ ). In this case, the mechanical behaviour is qualified as super plastic. The present investigation aims at evaluating and understanding the formability of Ti-6Al-

1 Université de Toulouse; INSA, UPS, Mines Albi, ISAE; ICA (Institut Clément Ader) - Campus Jarlard - 81013 ALBI Cedex 09 - France

2 Now at department of Advanced Materials Science Faculty of Engineering, Kagawa University, 2217-20 Hayashi-cho, Takamatsu, Kagawa 761-0396, Japan

3 Institute for Materials Research, Tohoku University, 2-1-1 Katahira, Aoba-ku 980-8577, Japan
$4 \mathrm{~V}$ alloy under hot forming conditions $\left(650^{\circ} \mathrm{C} \leq \mathrm{T}\right.$ $\leq 750{ }^{\circ} \mathrm{C}$ ) quite different from the conditions usually considered in super plastic forming [1]. To fulfil these objectives, it was necessary to establish accurate material models and predict microscopic material evolution depending on temperature and strain rate. Two kinds of microstructure were investigated, the first one considers a conventional grain size of the $\alpha$-phase $(3 \mu \mathrm{m})$ whereas a combined forging-rolling process was used to elaborate the second one and allows to obtain a very fine grain of the $\alpha$-phase $(500 \mathrm{~nm})[2,3]$. In this research work, we propose to investigate the capabilities of the titanium alloy under forming conditions by considering lower tem-

Corresponding author: V. Velay, Université de Toulouse, INSA, UPS, Mines Albi, ISAE; ICA (Institut Clément Ader), Campus Jarlard, 81013 ALBI Cedex 09, France, E-Mail: vincent.velay@ mines-albi.fr 


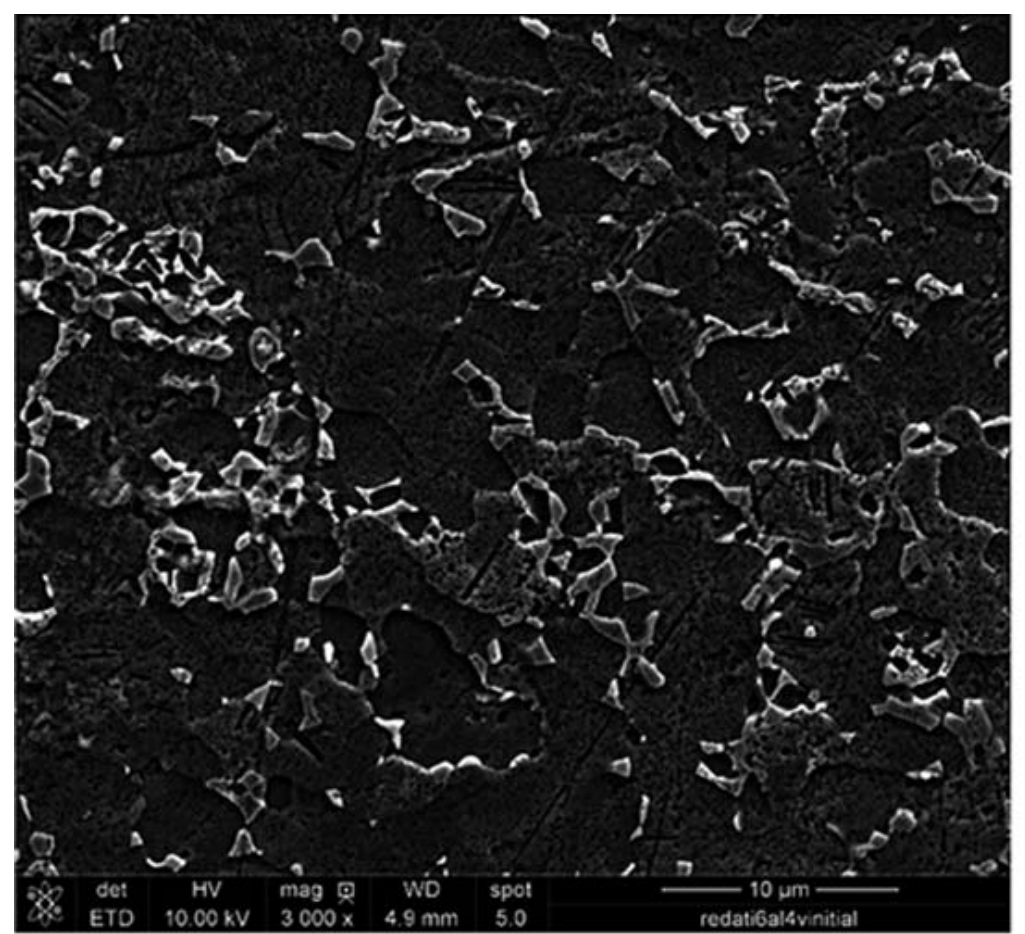

(a)

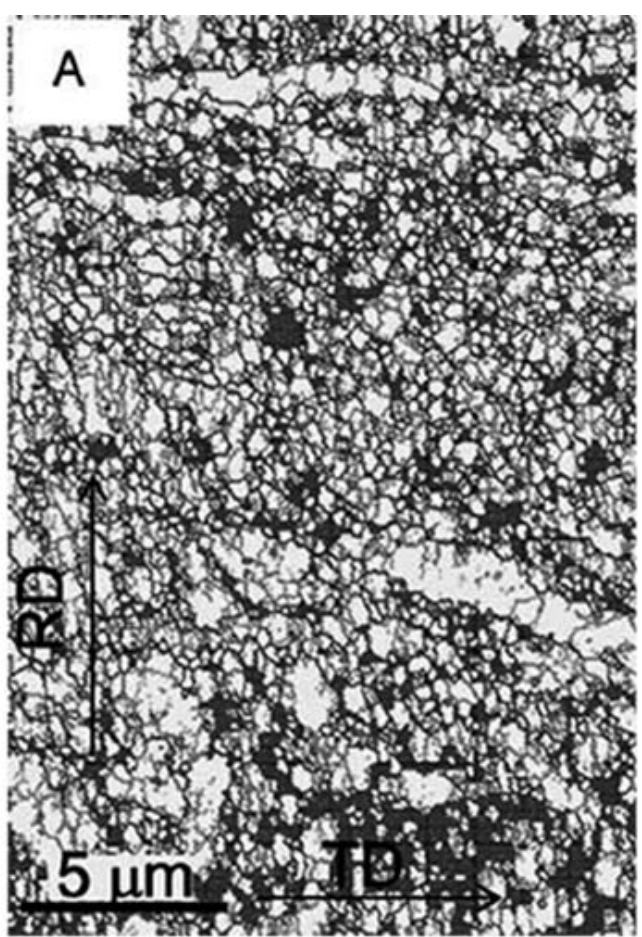

(b)

Figure 1. Starting microstructure (a); ultrafine grained microstructure (b)

peratures and higher strain rates. The following tasks were conducted:

- Setting up and carrying out of tensile tests at different temperatures and strain rates. From the experimental data, appropriate constitutive equations describing the tensile behaviour as a function of the temperature and the strain rate sensitivity were selected [4-6].

- An identification procedure of the model parameters has been implemented. It includes different stages. First, a manual calibration was considered in order to determine separately the viscosity and the hardening components, then an optimisation procedure was introduced by minimizing the gap between the experimental and simulated stress responses. This procedure includes different target strain rates. Last, an inverse analysis allows to determine the final set of parameters by coupling the optimisation procedure to a finite element calculation. It takes into account the sample shape and the real boundary conditions applied.

\section{Experimental investigation - Materials and testing}

A plate with a thickness of $4 \mathrm{~mm}$ was hot-rolled to provide the Ti-6Al-4V alloy sheets. Different microstructures were compared, the first one, hereafter designed as starting microstructure (SM), was the most widely used under superplastic forming conditions. It considers equiaxed $(\alpha+\beta)$ Ti-6Al-4V alloy with an average $\alpha$-phase grain size of $3 \mu \mathrm{m}$, Fig. la. A second kind of micro structure, hereafter designed as ultrafine grained microstructure (UFGM), was obtained using a combined forging-rolling process providing plates with a thickness from $1.4 \mathrm{~mm}$ to $1 \mathrm{~mm}$ and an average grain size of $500 \mathrm{~nm}[2,3]$, Fig. $1 \mathrm{~b}$.

The mechanical tensile tests were performed using a servo-hydraulic testing machine and a furnace accurate for the very large elongations. It includes three heating zones controlled by S-thermocouples and allows to maintain a constant temperature during all the sample deformation. As the use of a classical extensometer was not possible due to the very large elongation, a non linear crosshead displacement was considered for all the mechanical tests in order to obtain a constant target strain rate $\dot{\varepsilon}$ at the center of 

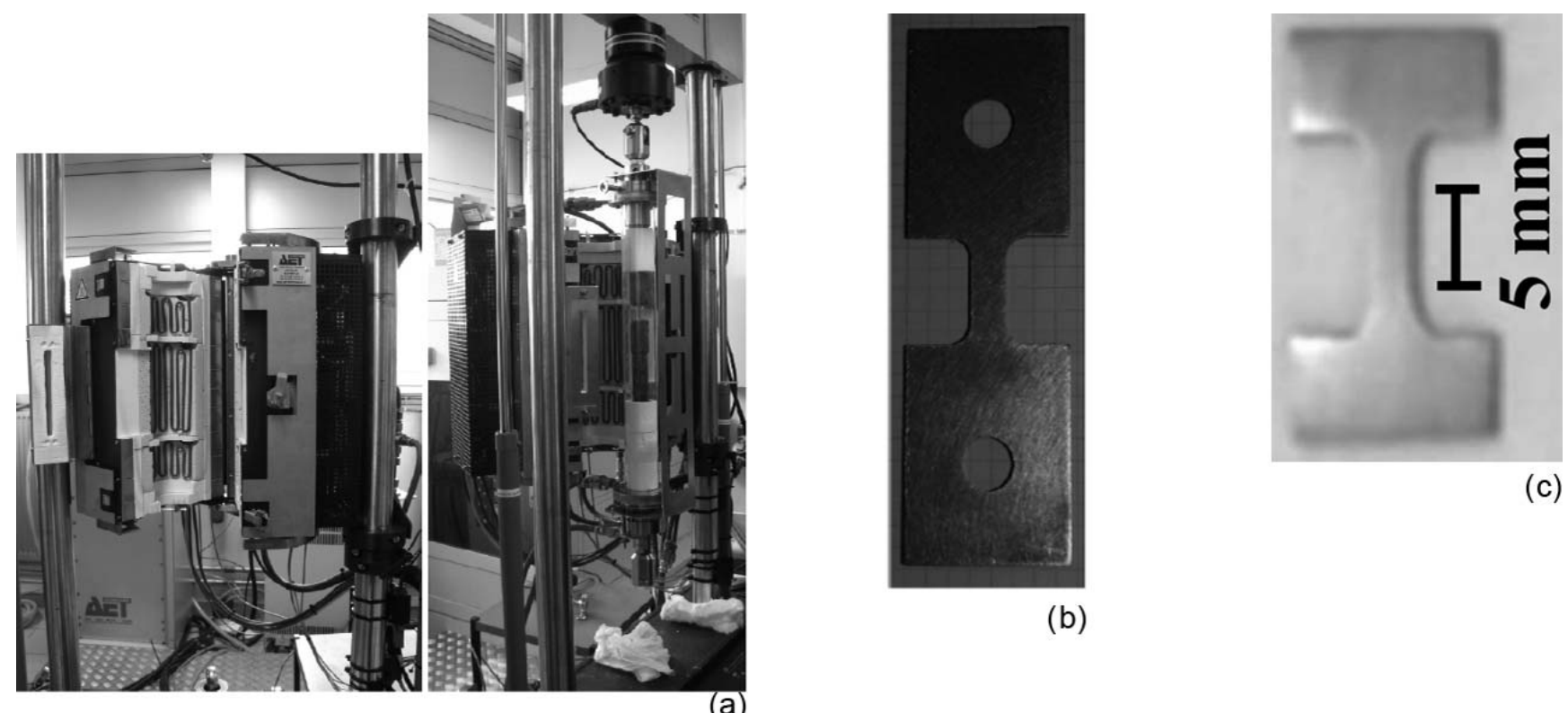

(c)

(b)

Figure 2. Experimental Set-up (a); Sample used for the mechanical tests at the Clément Ader institute (b), at the the Tohoku University (c)

the specimen. Thus, the time variation of applied displacement $u(t)$ was provided by Eq. (1) [7, 8]. Afterwards, the true strain $\varepsilon_{\mathrm{t}}$ and the true stress $\sigma_{\mathrm{t}}$ evolutions were calculated from the value of displacement $\mathrm{u}(\mathrm{t})$ given by the previous equation Eqs. (2), (3).

$\mathrm{u}(\mathrm{t})=\mathrm{l}_{0}\left(\mathrm{e}^{\dot{\varepsilon} \mathrm{t}}-1\right)$

$1_{0}$ is the initial gauge length, $\dot{\varepsilon}$ is the target strain rate and $t$ the time.

$\varepsilon_{\mathrm{t}}=\log \left(1+\frac{\mathrm{u}(\mathrm{t})}{\mathrm{l}_{0}}\right)$

$\sigma_{\mathrm{t}}=\frac{\mathrm{F}}{\mathrm{S}_{0}}\left(1+\frac{\mathrm{u}(\mathrm{t})}{\mathrm{l}_{0}}\right)$

$\mathrm{F}$ is the strength registred by the load sensor of the equipment and $S_{0}$ the initial section of the specimen.

Depending on the microstructure, some of the mechanical tests were performed at the Clément Ader
Institute, other ones were conducted at the Tohoku University. The capabilities of each equipement are similar, the main difference concerns the sample shape. Figure 2a shows a view of the experimental set-up available at the Clément Ader Institute with the sample used, Fig. 2b. Figure 2c illustrates the sample used at the Tohoku University.

All the test conditions are illustrated in Table 1. Three levels of temperatures from $650{ }^{\circ} \mathrm{C}$ to $750{ }^{\circ} \mathrm{C}$ and different strain rates from $10^{-4} \mathrm{~s}^{-1}$ to $10^{-2} \mathrm{~s}^{-1}$ were considered. The comparison between both microstructures (ultrafine grained microstructure and starting microstructure) was only performed at the higher test temperature $\left(\mathrm{T}=750^{\circ} \mathrm{C}\right)$.

\section{Results}

Figure 3 shows the stress-strain response for both microstructures and a temperature of $750{ }^{\circ} \mathrm{C}$. Several comments can be addressed. First, the strain rate sensitivity of the materials was quite significant.

Table 1. Test conditions for the starting microstructure $(\dagger)$ and for the ultrafine grained microstructure $(\ddagger)$

\begin{tabular}{llllll}
\hline & $10^{-2} \mathrm{~s}^{-1}$ & $5 \cdot 10^{-3} \mathrm{~s}^{-1}$ & $10^{-3} \mathrm{~s}^{-1}$ & $5 \cdot 10^{-4} \mathrm{~s}^{-1}$ & $10^{-4} \mathrm{~s}^{-1}$ \\
\hline $750{ }^{\circ} \mathrm{C}$ & $\dagger$ & $\dagger$ & $\dagger$ & $\dagger$ & $\dagger$ \\
$700{ }^{\circ} \mathrm{C}$ & $\ddagger$ & $\ddagger$ & $\ddagger$ & $\ddagger$ & $\ddagger$ \\
$650^{\circ} \mathrm{C}$ & $\ddagger$ & $\ddagger$ & $\ddagger$ & $\ddagger$ & $\ddagger$ \\
\hline
\end{tabular}



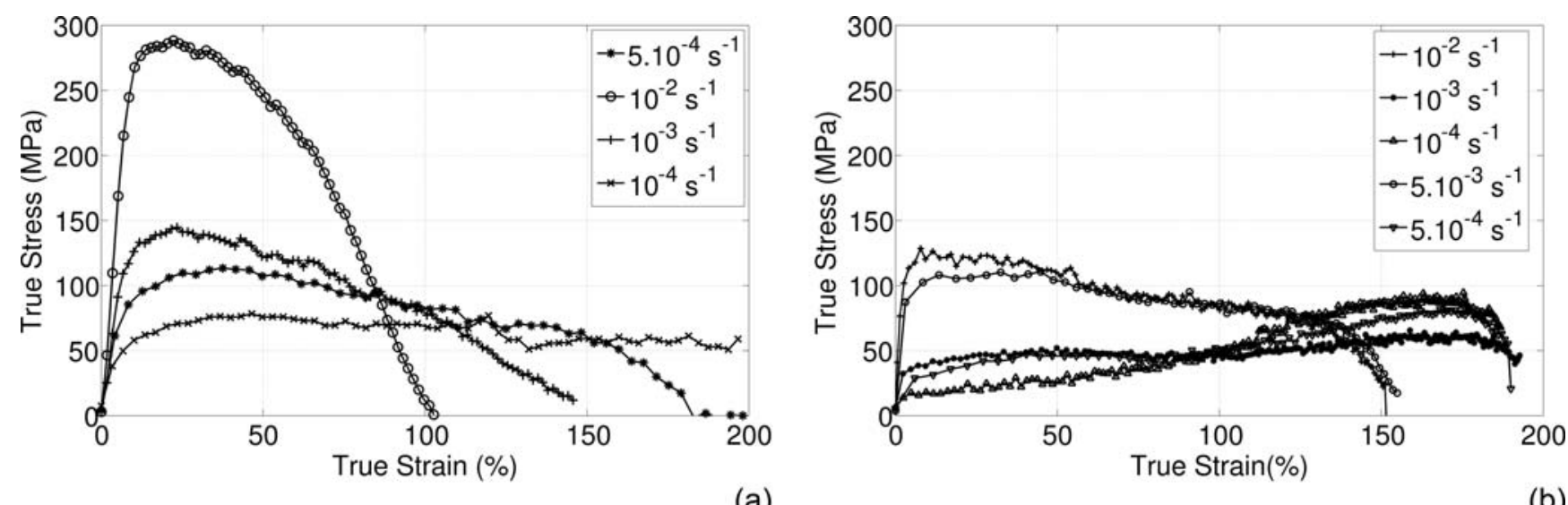

(a)

Figure 3. Stress-strain response at $\mathrm{T}=750^{\circ} \mathrm{C}$ and different strain rates for the starting microstructure (a) and the ultrafine grained microstructure (b)

Secondly, the ultrafine grained microstructure allows a very important elongation whatever the strain rate considered. Indeed, even for the higher strain rate, an elongation around $60 \%$ can be reached whereas necking occurs from an elongation of $20 \%$ for the starting microstructure under the same test conditions. Moreover, the ultrafine grained microstructure exhibits a second hardening phase occuring for the lower temperatures. This effect is mainly due to the increase of the grain size activated by the high temperature exposure time $\left(\dot{\varepsilon}=5 \cdot 10^{-4} \mathrm{~s}^{-1}, 10^{-4} \mathrm{~s}^{-1}\right)$.

Thus, the ultrafine grained microstructure presents an improved mechanical behaviour. Moreover, these enhanced properties are maintained at lower temperatures at $\mathrm{T}=650{ }^{\circ} \mathrm{C}$ (a) and $\mathrm{T}=600^{\circ} \mathrm{C}$ (b), Fig. 4 .

Indeed, an elongation of $30 \%$ can be reached before necking for the higher strain rate and for both temperature levels.

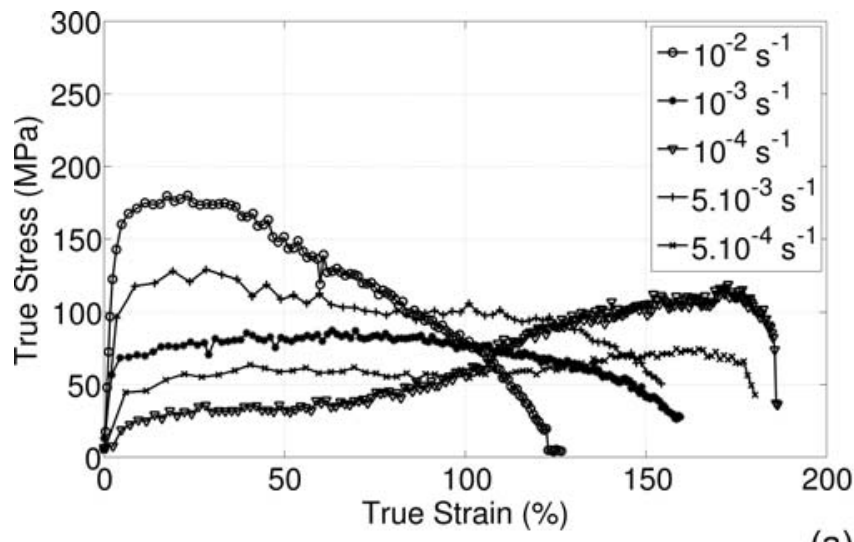

\subsection{Behaviour modelling}

\subsubsection{Model formulation}

The present work considers unified superplastic constitutive equations [4-6]. This modelling framework is in a good agreement with the principles of the irreversible processes of thermodynamics. The model includes a von Mises yield criterion Eq. (4) in order to define the elastic domain, an isotropic hardening law to describe the plastic behaviour Eq. (5) and a viscoplastic flow considered as a power law of the yield criterion to take into account the strain rate sensitivity Eq. (6).

$\mathrm{f}=\mathrm{J}(\bar{\sigma})-\mathrm{R}-\sigma_{0}=\left(\sqrt[\frac{3}{2}]{\overline{\mathrm{S}}: \overline{\mathrm{S}}}\right)-\mathrm{R}-\sigma_{0}$

with $\overline{\mathrm{S}}$ the deviatoric part of the Cauchy Stress $\bar{\sigma}, \mathrm{R}$ the isotropic hardening, $\sigma_{0}$ the elastic limit.

$\mathrm{R}=\mathrm{Q}\left(1-\mathrm{e}^{-\mathrm{bp}}\right)$

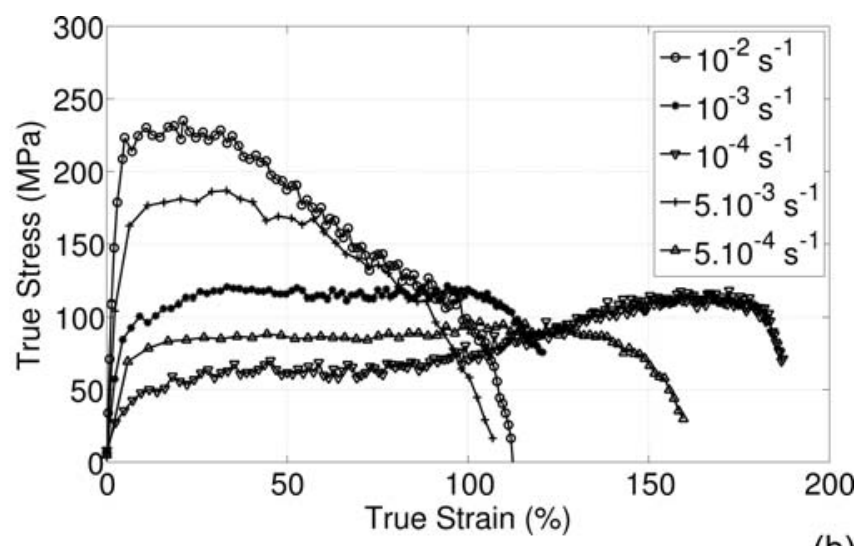

(b)

Figure 4. Stress-strain response at $\mathrm{T}=700^{\circ} \mathrm{C}(\mathrm{a})$ and $\mathrm{T}=650^{\circ} \mathrm{C}$ (b) for different strain rates (ultrafine grained microstructure) 
$\mathrm{Q}$ and $\mathrm{b}$ are material parameters and $\mathrm{p}$ the effective plastic strain defined by Eq. (6).

$\dot{\mathrm{p}}=\left(\frac{\mathrm{f}}{\mathrm{K}}\right)^{\mathrm{n}}$

$\mathrm{K}$ and $\mathrm{n}$ are material parmeters.

Moreover, the multiaxial plastic strain rate, $\overline{\dot{\varepsilon}_{\mathrm{p}}}$, for viscoplastic materials implemented within a large deformation are given by Eq. (7), and the Jaumann rate $\bar{\sigma}$ of the Cauchy Stress is provided by Eq. (8).

$\overline{\dot{\varepsilon}_{\mathrm{p}}}=\frac{3}{2} \dot{\mathrm{p}} \frac{\overline{\mathrm{S}}}{\mathrm{J}(\bar{\sigma})}$

$\check{\bar{\sigma}}=\lambda \operatorname{Tr}\left(\overline{\dot{\varepsilon}_{\mathrm{e}}}\right)+2 \mathrm{G} \overline{\dot{\varepsilon}_{\mathrm{e}}}$

$\overline{\dot{\varepsilon}_{\mathrm{e}}}$ is the rate of elastic deformation written as Eq. (9). $\mathrm{G}$ is the shear modulus and $\lambda$ is the Lamé constant.

$\overline{\dot{\varepsilon}_{\mathrm{e}}}=\overline{\dot{\varepsilon}_{\mathrm{T}}}-\overline{\dot{\varepsilon}_{\mathrm{p}}}$

with $\overline{\dot{\varepsilon}_{\mathrm{T}}}$ the rate of the total deformation.

The model requires the identification of several parameters which are the Young modulus E through the calculation of the shear modulus $G$ and the Lamé constant, the Poisson ratio will be taken to 0.3 , the hardening parameters $\mathrm{Q}$ and $\mathrm{b}$ and the viscoplastic flow rule coefficents $\mathrm{K}$ and $\mathrm{n}$.
These multiaxial constitutive equations were implemented into a large strain finite-element solver ABAQUS through the user defined subroutine CREEP in order to perform numerical simulations at the scale of the sample.

\subsubsection{Identification procedure}

The methodology can divided into three different stages:

- Step 1: a manual identification was performed to determine the hardening parameters $Q$ and $b$ (respectively the viscosity parameters $K$ and $n$ ) without considering the parameters of the viscosity (respectively the hardening parameters)

- Step 2: an optimisation process, using the parameters provided in the previous step as initial set, was implemented at the scale of the representative elementary volume (REV) in order to reproduce the stress-strain response by minimizing the gap between the experimental and calculated stress.

- Step 3: an optimisation process was performed at the scale of the sample, the step requires the implementation of an inverse analysis combining a FE Simulation and an optimization toolbox. The objective function was defined to minimize the gap between the experimental and calculated force.

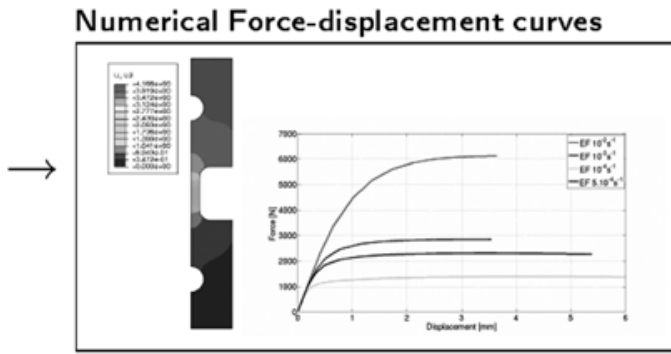

Experimental Force-displacement curves

(CREEP.f User Subroutine)

- Application of a non uniform boundary condition

(DISP.f User Subroutine)

- Starting parameter set provided by the Stage 2

of the identification procedure

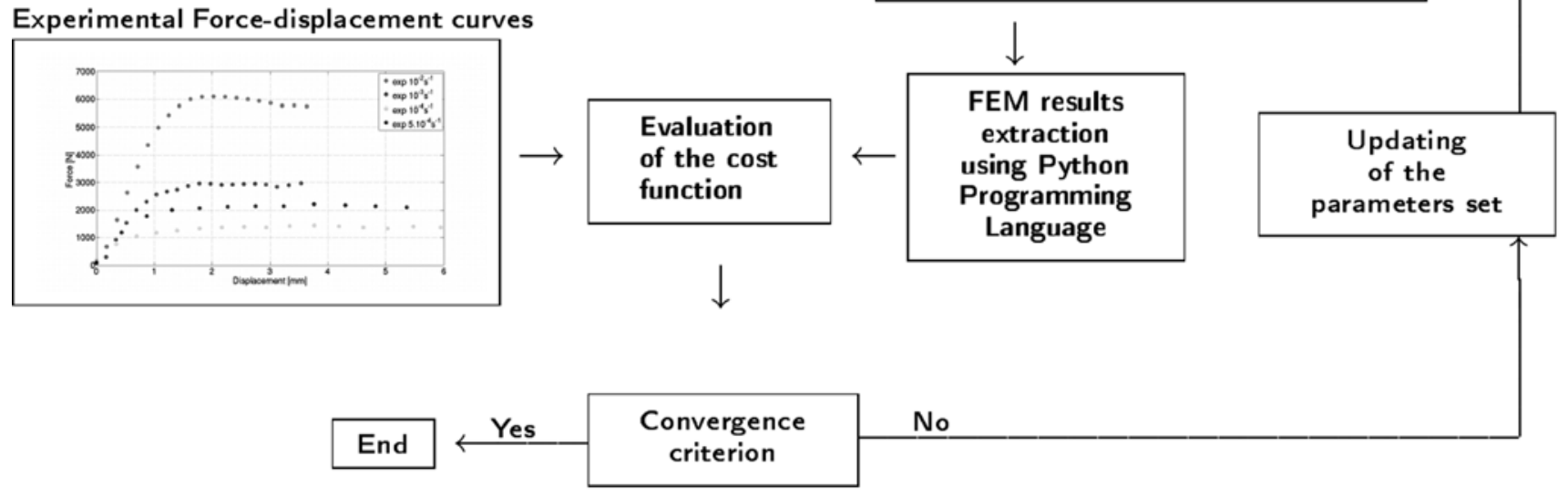

Figure 5. Implementation of the inverse analysis using FE simulations 

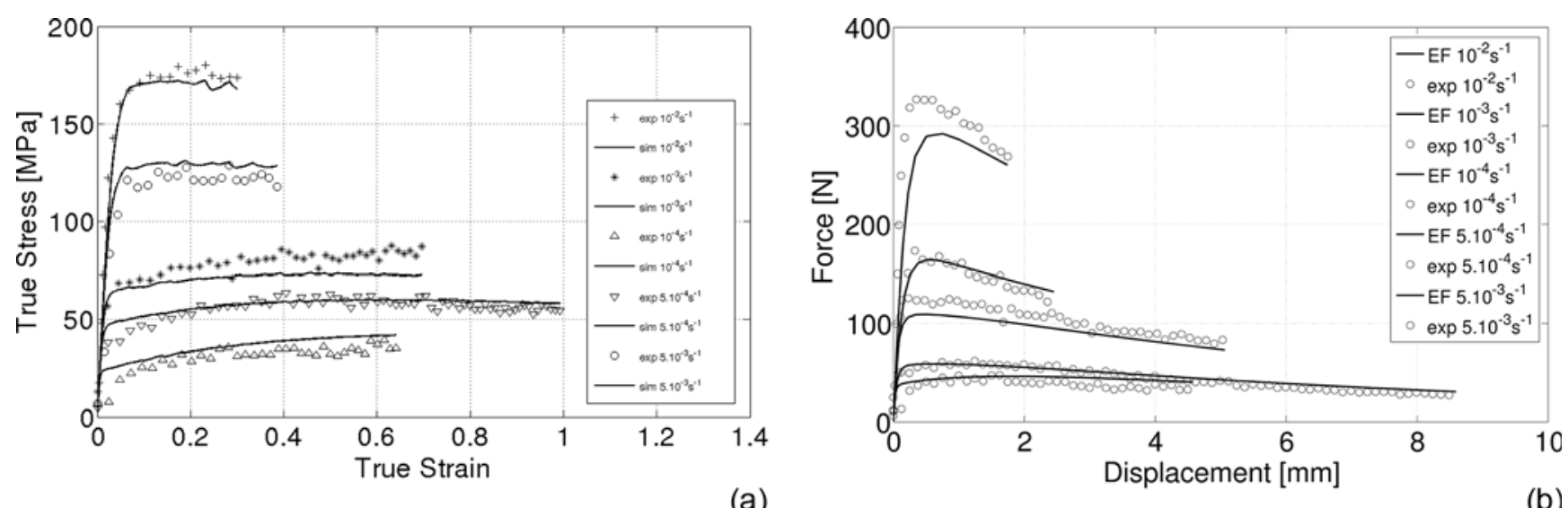

(a)

Figure 6. Comparison of the stress-strain response provided at the scale of the representative elementary volume (a) and of the Force-displacement response at the scale of the specimen (b) $-\mathrm{T}=700{ }^{\circ} \mathrm{C}$ for the ultrafine grained microstructure at the end of Step 2.

The global methodology described in Step 3 was illustrated in Fig. 5. First, a direct FE simulation was performed with the set of parameters identified at the end of the Step 2. The FE simulation requires the implementation of two user defined subroutines. The first one (CREEP.f) allows the introduction of the behaviour model and a non linear evolution of the applied displacement was considered through the second one (DISPL.f). Afterwards, the calculated force was extracted from the result file using a Python programming script. Then, the objective function of the optimisation problem consists in minimizing the gap between the experimental and calculated force. If the convergence criterion was achieved, the optimised set of model parameters was obtained, if not, the parameter set had to be updated and a new FE simulation had to be launched.

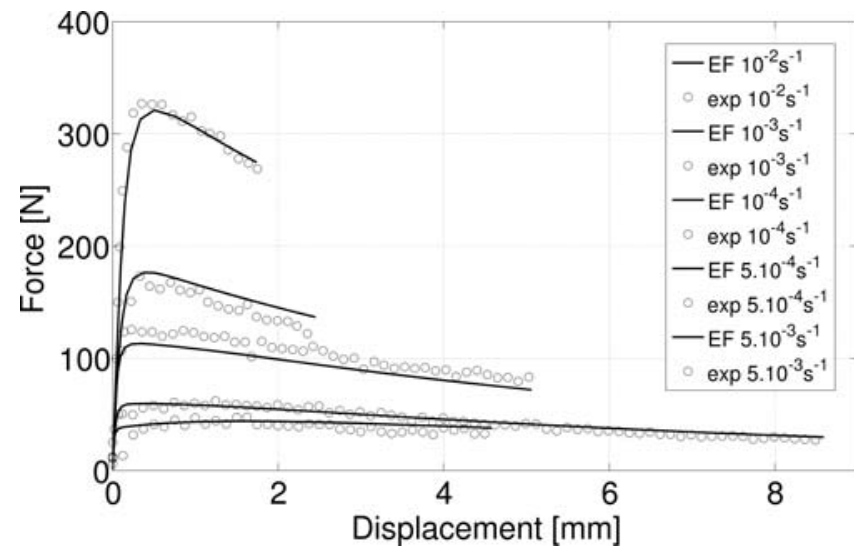

Figure 7. Comparison of the Force-displacement response at the scale of the specimen $-\mathrm{T}=700^{\circ} \mathrm{C}$ for the ultrafine grained microstructure at the end of the Step 3
Figure 6 shows the results provided at the end of the Step 2 for the ultrafine grained microstructure and a temperature of $700{ }^{\circ} \mathrm{C}$. Figure 6a illustrates the stress-strain response at the scale of the representative elementary volume, a good agreement is given after optimisation of the model parameter set. However, the comparison between calculated force versus Displacement provided by a FE simulation at the scale of the sample and experimental force shows some discrepancies, Fig. 6b. Hence, the Step 3 allows to improve the values of the model parameters and provides a better description of the force evolution whatever the strain rate and the temperature levels. Fig. 7 shows an example of the results at the end of Step 3 for the ultrafine grained microstructure and $\mathrm{T}=700{ }^{\circ} \mathrm{C}$.

Table 2 provides the model parameters identifed for the ultrafine grained microstructure at $\mathrm{T}=700^{\circ} \mathrm{C}$.

\section{Conclusion}

The present investigation aims at evaluating and understanding the formability of Ti-6Al-4V alloy under hot forming conditions $\left(650{ }^{\circ} \mathrm{C} \leq \mathrm{T} \leq 750{ }^{\circ} \mathrm{C}\right)$. Two kinds of microstructure were evaluated in such forming conditions. First, the classical Ti-6Al-4V alloy microstructure with an average grain size of $3 \mu \mathrm{m}$ and an optimised one with an ultrafine grained microstructure of $0.5 \mu \mathrm{m}$ able to enhance the mechanical properties for lower forming temperatures and higher strain rates. Constitutive behaviour laws were identified, the model is able to take into account several effects like the hardening or the strain 
Table 2. Model parameters identified at the end of the Step 3 for the ultrafine grained microstructure and $\mathrm{T}=700{ }^{\circ} \mathrm{C}$

\begin{tabular}{llllll}
\hline$E[\mathrm{MPa}]$ & $\sigma_{0}[\mathrm{MPa}]$ & $\mathrm{K}\left[\mathrm{MPa} \cdot \mathrm{s}^{1 / \mathrm{n}}\right]$ & $\mathrm{n}$ & $\mathrm{Q}[\mathrm{MPa}]$ & $\mathrm{b}$ \\
\hline 7070 & 10 & 1490 & 2.20 & 27 & 2.50 \\
\hline
\end{tabular}

rate sensitivity. It will be improved in a future work by introducing the grain size evolution due to the temperature and the inelastic deformation during the forming process. Presently, phase characterization $(\alpha-\beta$ phases) and microstructural analysis (grain size, defects) before and after tensile tests by using mainly scanning electron microscopy images and optical metallography are also investigated. Results are intended to understand the relationship between mechanical properties and microstructure evolution at high temperatures and also to have a first assessment of the deformation mechanisms in link with the macroscopic stress-strain curves. At last, anisotropy of the sheet should also be investigated in the future.

\section{References}

[1] E.-L. Odenberger, R. Pederson, M. Oldenburg, Mater. Sci. and Eng. 2008, A 489, 158.
[2] H. Matsumoto, K. Yoshida, S.-H. Lee, Y. Ono, A. Chiba, Materials Letters 2013, 98, 209.

[3] H. Matsumoto, L. Bin, S.-H. Lee, Y. Li, Y. Ono, A. Chiba, Metallurgical and Materials Transactions 2013, A 44, 3245.

[4] J. Lin, T.A. Dean, Journal of Materials Processing Technology 2005, 167, 354.

[5] J. Lin, International Journal of Plasticity 2003, $19,469$.

[6] B.H. Cheong, J. Lin, A.A. Ball, Journal of Materials Processing and Technology 2001, 119, 361.

[7] P.N. Comley, Journal of Materials Enginering and Performance 2008, 17, 183.

[8] W. Pan, M. Krohn, S. Leen, T.H. Hyde, S. Walloe, Journal of Materials Design and Applications 2005, 219, 149. 